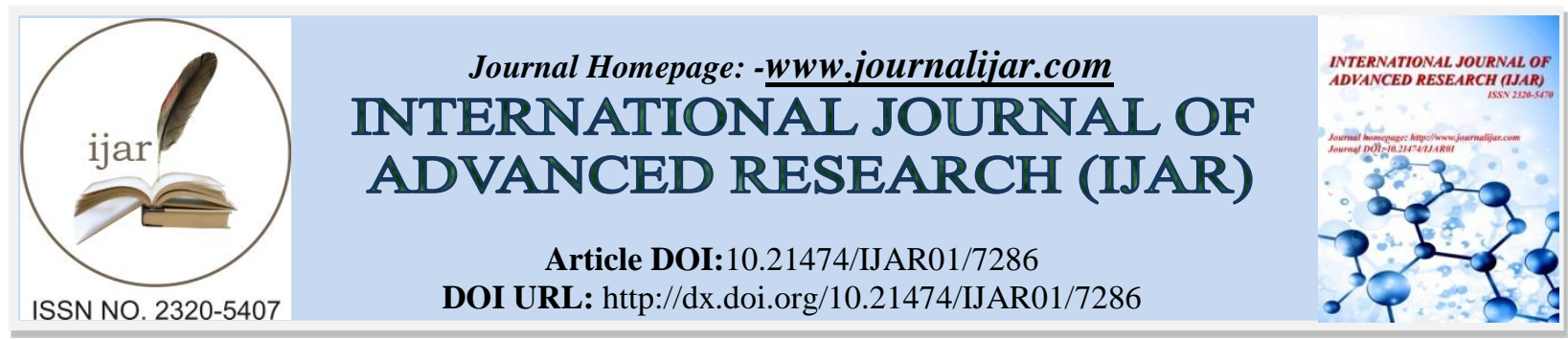

RESEARCH ARTICLE

\title{
JOB REDUNDANCY AS A STRATEGIC OPTION FOR MNES AND ITS RIGHT IMPLEMENTATION TECHNIQUE.
}

Joy Munshi.

CEO, American Institute of Management Science, Tx 75080 Currently doing a research on Redundancy at Western Sydney University, Australia.

\section{Manuscript Info}

Manuscript History

Received: 14 April 2018

Final Accepted: 16 May 2018

Published: June 2018

\begin{abstract}
During the last few decades, there has been a significant rise in job redundancy around the world. MNEs have been applying redundancy as a cost-cutting and rejuvenating strategy besides using it for surviving and retaining their business during tough times. However, the practice has evidently failed to result in expected outcomes in many countries including Australia, the UK and in the USA. This study has examined the link between redundancy as a cost-cutting strategy, and its effectiveness as a cost-reduction, rejuvenation and business retention strategy of MNEs. In order to do so, the researcher has critically analysed the related literature, and then critically evaluated the practice from various business contexts. Notably, contrary to the beliefs and practices of MNEs, the research reveals that redundancy is not such an effective long-term strategy for a firm's survival and business retention, as it is thought. At the same time, the researcher has developed a model called 'Best Fit Redundancy Model' that can help MNEs to apply the strategy more effectively and responsibly, if redundancy is the only and ultimate strategic option for them.
\end{abstract}

Copy Right, IJAR, 2018,. All rights reserved.

Rise in Redundancy: An Overview:-

Job redundancy has become a common strategic preference of MNEs around the world for the last few decades (Awino, 2017). According to Doherty (2010), organisational structure, philosophy, focus and priorities of MNEs change frequently due to sudden and frequent changes in their external environment, and as a consequence, unplanned redundancy has become a central plank of their contingency plan in order to cope up with these unexpected changes. Moreover, redundancy is also implemented followed by technological advancement, which require MNEs to recruit technologically skilled manpower, which ultimately replaces existing staff members (Thompson and Martin, 2010).

While redundancy is frequently used as a 'Turn-around' or 'Recovery' Strategy, its expected outcomes have still remained ambiguous (Mellahi and Wilkinson, 2010). Again, as Newton (2011) opines, success of an MNE largely depends on its skilled and dedicated manpower, but impulsive redundancies greatly affect a firm's primary activities and push it to the risk of collapse due to skill-shortage (Smithers, 2010). It is, therefore, a burning question whether redundancy as a strategic choice is effective, appropriate and ethical for organizations to use as a survival or turnaround technique especially when the invaluable contribution of employees in the success of MNEs is considered. 
Nevertheless, there has been a significant rise in redundancies around the world (Mellahi and Wilkinson, 2010; p.2). Especially during or followed by recessions, redundancies in private sector have become a common phenomenon (Dibben, Klerck and Wood, 2011; p.284) leaving millions of people jobless. As a reports go, UK unemployment broke though 'the 2.5 million mark' by April 2010 as a consequence of the last recession (Wearden, 2010), while Australian employers has kept even higher and alarming rates of redundancies (Patty, 2016). And the impacts of such redundancies are severe. It often destroys the hard-earned competitive position of the firm (Guterman, 2009; p.3) and at the same time, forces the firm to concede considerable direct and indirect costs (Gandolfi, 2010). Therefore, redundancy as a strategy demands to analysed further to determine its effectiveness and impacts on MNEs.

\section{Redundancy from the Academic Context:-}

In human resource management literature, redundancy refers to the dismissal that is in general based on operational reasons, especially when commercial and economic aspects of the business are considered by the authority. It occurs if an employee is dismissed not for performance or personal act, but purely because the role previously performed by the employee is no more needed by the employer. Redundancy, therefore, particularly refers to the termination of a position, not a person (Stone, 2014; pp.145), while dismissals are the outcomes of disciplinary issues or of job performance (Fazey, 2010; pp.260). Redundancy - especially compulsory redundancy - is considered to be the 'last resort' and the least acceptable face of downsizing (Redman and Wilkinson, 2017; p.396).

By definition, redundancy is 'one of the potentially fair reasons for dismissal' and is wholly or mainly attributed to the fact that the employer has ceased or intends to cease to carry on the business for which the employee in question was appointed or engaged, or to carry on the business at a particular location at which the employee was employed, or to diminish the requirements of the business, or the employee to carry our work of a particular kind (Pilbeam and Corbridge, 2010; pp.565).

While redundancy often comes as a part of strategic HR Planning of MNEs in order to address changes in external environment (Pilbeam and Corbridge, 2010; pp.566), firms often consider is as a 'recovery strategy', 'costreduction strategy', turnaround strategy', or strategy to rejuvenating mature business (Thompson and Martin, 2010; pp.603-611). It is a fact that today's business world is full of ups and downs - thereby quite neoteric in nature and to cope up with the ever-changing and uncertain world, redundancy occurs in order to enable the MNEs to succeed in abrasive business cycle with the right levels of recruitment. More importantly, companies announce redundancy as an integral part of their planned downsizing strategy as well (Bergstorm and Arman, 2016). Causes of redundancy, therefore, include Structural decline in a sector or industry, decrease in the level of economic activity affecting sales or income of the firm, technological changes taken places within the organization or across the sector, and reorganization or restructuring within the organization with a view to making more efficient use of workforce and equipment (Pilbeam and Corbridge, 2010).

In summary, while redundancy can occur as a result of organisational needs to streamline its operations, foreseen crisis, or even poor HR Planning (Foot and Hook, 2015), corporate restructuring and coping up with global scale of changes also cause redundancy (Pilbeam and Corbridge, 2010). According to Gandolfi and Hansson (2010), redundancy - often termed as 'reduction in force (RIF)' - is a measure applied to eliminate cost. Whatever the cause is, effective and befitting policies for the management of redundancy is very crucial for MNEs, because redundancy programmes not only produce considerable amount of conflict, but also generate ill-feeling and bad publicity for a business entity (Fazey, 2010).

\section{Redundancy and Strategic Human Resource Planning:-}

Redundancy as a strategic option and the strategic human resource planning of MNEs has a strong correlation. As Nyasha (2016) states, redundancy often occurs as part of a strategic human resource planning of MNEs with a view to achieving certain business goals. Firms use the tool as a business recovery and cost reduction strategy adapted to rejuvenate a mature business as well (Thompson and Martin, 2010, pp.603-611). It is to note that redundancy is not always a consequence of external changes in business environment, but MNEs deliberately use it as planned downsizing tool to minimize their cost and in some cases, to cope up with abrasive business cycle within the industry or marketplace, which is in other words simply a strategic tool of MNEs used in line with their corporate strategy (Lewis, 1993; p.3). With this end of view, redundancy seems to be used going beyond its definition and meaning, as it does not mean simply to cut workforce, but to abolish existing positions (Stone, 2014; pp.145). Unfortunately, redundancy is adapted by MNEs as a well-planned strategy to reducing cost and improving organizational performance (Naysha, 2016; Chan, 2013). 


\section{Why Redundancy Situations Occur:-}

While downsizing through redundancy has become a common practice of organisations and thereby, gained 'strategic legitimacy' since 1980's (Redman and Wilkinson, 2009; p.381), academic literature differs this view and states that redundancy may occur for four main reasons.

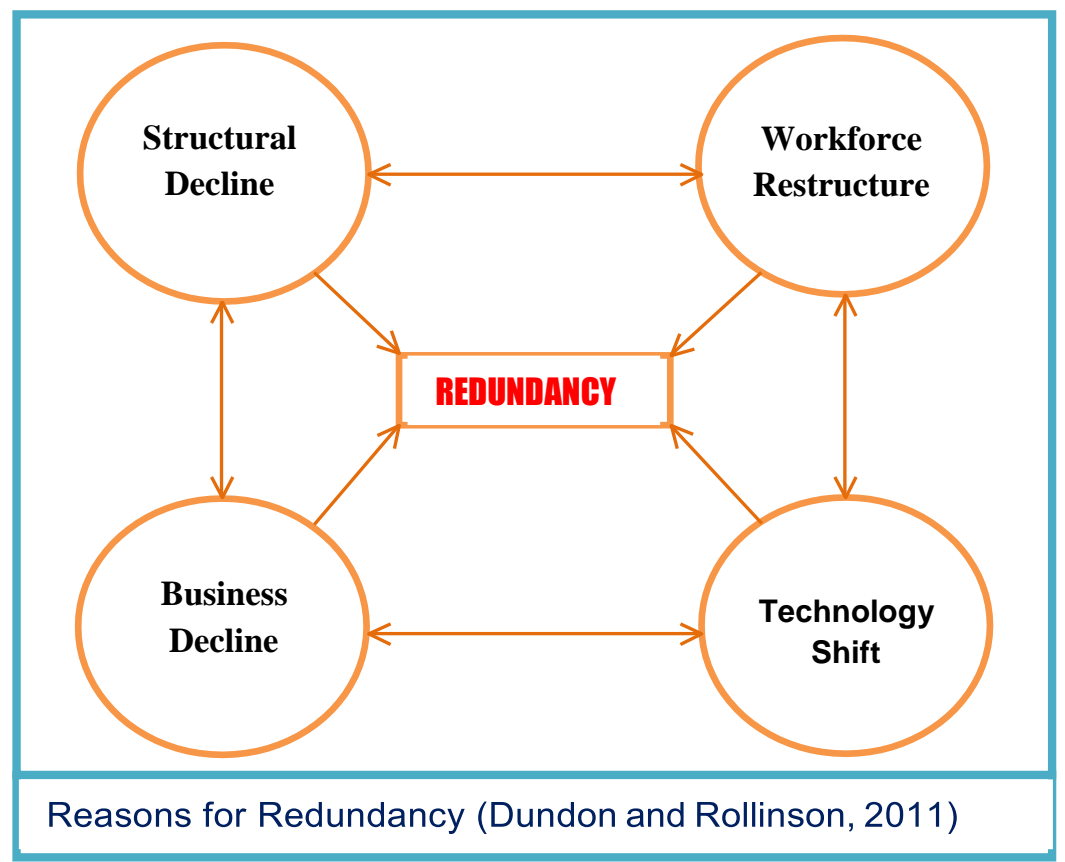

Structural decline refers to the situation when a business closes down its operations in a particular place, while workforce restructuring means reorganizing human resources of a firm in order to improve its performance and turn around in their business. Technological shift, on the other hand, refers to the situation where a firm adapts new technology and brings automation to its operations. Finally, business decline is when a business concedes a consistent loss or decrease in its sales and profits, and unable to maintain its overall financial strength. And as Sheehan (2015) states, "in cases of dismissal by reason of redundancy, it is imperative for the employer to prove that the redundancy is in fact a legitimate redundancy and that the decision to dismiss was fair in all circumstances. To prove the existence of a genuine redundancy situation an employer must demonstrate that the employee's job ceases to exist, and the employee is not replaced. This can arise for a number of reasons including rationalization, reorganisation, not enough work, the financial state of the business, business closures etc."

\section{Redundancy as a Strategic Choice for MNEs:-}

MNEs widely use redundancy as a cost-cutting and profit enhancing strategy, because the human capital expense of a business may represent up to $70 \%$ of their operational cost (Hyland, 2010; p.6). Therefore, redundancy on the face of it seems to be a very useful tool, although the term does not simply refer to cutting workforce (Stone, 2014). Nonetheless, the effects and aftereffects of this practice are often severe, because firms keep struggling followed by redundancy execution for maintaining their 'engagement and performance level' in the market (Organisational Response to the Financial Cricis, 2010). As Kalimo et. al. (2003) states, redundancy undoubtedly increases stress level of existing staff, and they feel insecure enough to be devoted to engagement, commitment and productivity. Nevertheless, MNEs are reducing workforce recklessly in the form of redundancy while the determination the success and impact of it has still remained inconclusive (Gandolfi, 2010).

\section{Cost Reduction and Redundancy:-}

As stated before, redundancy is primarily applied by firms is to reduce their operational cost. Human resources is in fact extremely costly and sometimes requires up to $70 \%$ of the total operational cost of a business (Hyland, 2010). However, while redundancy by definition is not a cost-cutting tool by slashing workforce, it has been debated whether reduction in work force can effectively reduce operational cost of a business (Naysha, 2016). Accoring to Gandolfi (2010), "Empirical evidence suggests strongly that the planning and conduct of RIF-related activities have considerable consequences for the organization and its many stakeholders. Therefore, the adoption of any RIFrelated activity is likely to produce considerable human consequences (Cascio, 2002). It is fair to say that 
organizations all over the world have underestimated the impact of RIF on the organizational culture (Cascio, 2003) and on the company's remaining workforce (Gandolfi, 2006). While firms generally anticipate immediate financial and non-financial outcomes (Sahdev, 2003), there is a substantial body of evidence suggesting that organizations have failed to adequately prepare for the human consequences following an RIF." Therefore, redundancy seems to be not 'fully recognised' a tool for cost reduction, especially its effects and aftereffects on existing workers and overall performance of the firm are considered.

\section{Profitability and Redundancy:-}

As a profit enhancing strategy, redundancy is often adapted by MNEs around the globe, although various research doubts its effectiveness all in all (Nyasha, 2016). Chalos and Chen (2002) reported that firms that downsize to focus their activity are likely to redirect the savings from downsizing unprofitable or unrelated lines of activities towards their core activities. However, Gandolfi (2010) states, "in the wake of the corporate mantras of 'profit maximization' and 'shareholder value', firms are continually trying to improve their overall efficiency, productivity, profitability, effectiveness, and competitiveness (Cravotta and Kleiner, 2001; Cascio, 2002). As a direct consequence, new management theories and concepts, sometimes cynically referred to as management fads, regularly emerge and are frequently, and at times desperately, adopted by companies trying to gain a competitive edge." Thus, rather than enhancing profitability, redundancy may lead the firm to a confused state that poses the risk of losing their competitive edge.

\section{Redundancy and Firm's Performance:-}

Redundancy can have serious effect on the performance of a business firm, mainly due to two main reasons. First, a sudden reduction in workforce breaks the value chain of the firm by reducing its competence to a great extent, and secondly, the survivors turn to be demoralized and lose their productivity (Gandolfi, 2010; Sutton, 2007). As porter (1990) describes, human resource management is only a supporting activity in the value chain of an MNE, where each staff is entrusted with a specific job, which redundancy jeopardizes to a great extent (Chan, 2013). Therefore, the practice needs to be thoroughly analyzed to determine whether it can enhance the performance of MNEs.

Undoubtedly, in today's volatile and uncertain world, the survival and success of any business entrant largely depend on its ability to cope with the fast moving external environments through restructuring, remodelling, and continual adjustments to the size and constitution of its systems and work-forces (Dibben, Klerck \& Wood, 2011; Mellahi \& Wilkinson, 2010; Gandolfi, 2010; Flower, 1993). Moreover, in order to maximize their efficiency, today's organisations opt to utilise their workforce through a primary focus upon redundancies (ACAS, 2010; Dundon \& Rollinson, 2009; Lewis, 1993). Nevertheless, while redundancy is an HR strategy adopted to boost up employee-efficiency (Foot \& Hook, 2011), the strategy has so far failed to produce its expected outcomes (Gandolfi, 2010).

\section{Redundancy and Fair HR Management:-}

Unquestionably, there exists an ethical dilemma whether employers should weaken people's morale and productivity by making them jobless with a sudden decision, while the economic strength of the company has been developed with significant contribution of the current workforce. While Gandolfi (2010) opines that redundancy has so far as a downsizing means produced considerable direct and indirect costs and generated adverse human consequences (p.8), related literature and enterprise agreements reveal that there is a clear lack of transparency in redundancy execution especially in selection procedures (Enterprise agreements of NAB, Commonwealth Bank, Westpac and ANZ). Interestingly, some of these agreements do not even explain what redundancy is, let alone describe redundancy procedure.

Again, as strategic workforce planning suggests, effective work design by using cognitive, physical, bio-mechanical and physio-social components can engage employees more into their work, and consequently a firm can save or reduce the need for workforce (Foot and Hook, 2011), which might result in redundancy situation as well. Similarly, as the Safe Work Australia (2017) determines, creating a conductive workplace using HOW-WHT-WHY Model helps get maximum output from workers. 


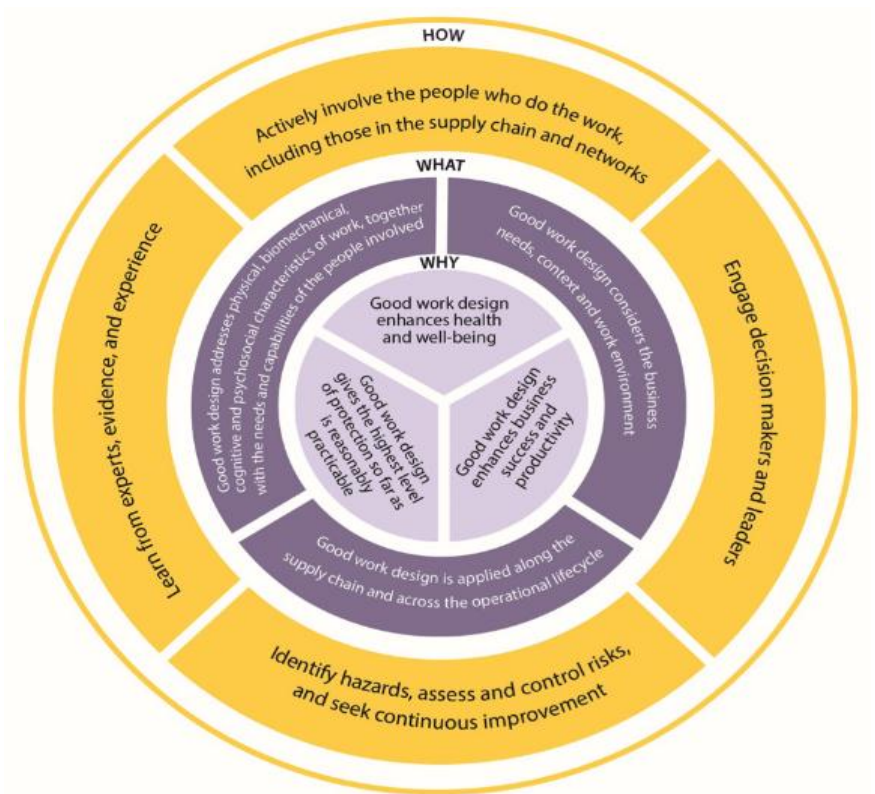

How-What-Why Model (Safe Work Australia, 2017)

As a firm's success largely depends on skilled, experienced and trustworthy workers, they need to retain their employees as long as practicable so that the business keeps receiving their exceptional services (Williams, D. K. and Scott, M. M 2012). Efficient strategic human resource planning along with effective training and standard compensation can help MNEs to retain their staff and thereby, eliminate redundancy situation, as stated by Chan (2013). Notably, the above theories do not refer redundancy as a cost cutting strategy, but encourage avoiding the situation for the sake of long-term organizational performance and competitive advantages. Yet, redundancy is frequently used as a cost-reduction and performance enhancing strategy by MNEs in Australia (O'Carroll, 2009) around the world (Harrington, 2016). In fact, redundancies are of then the first choice MNEs often turn to while needing to cut their cost (Makin, 2013). Notably, the strategy is often used to cut heads only in the form of a valid reason (Stern, 2012), although by definition redundancy is abolishing a position, not just terminating a person (Stone, 2014). Therefore, such redundancy is clearly falling in unfair dismissal (Fazey, 2010), and refers to unethical human resource practices.

\section{The effectiveness of redundancy as a Strategy:-}

Redundancy, therefore, is an ambiguous practice and has so far failed to produce its expected outcomes (Gandolfi, 2010). In many theories, it is considered as an effective survival strategy to cost-cutting, because human capital expenses, as mentioned earlier, often represents $70 \%$ of the operating cost (Hyland, 2010; p.6). However, various researches have proven that redundancy does not improve financial performance (Mellahi \& Wilkinson, 2010; Cascio, 2005) and thereby, fails to cut cost due to considerable expenses going with compensations and other hidden expenses (Sands, 2009). It is also apparent that unplanned redundancy during downturns is a great threat to the value-chain of the organisation and thereby, poses dangers of closing down operations and poor customer service (Naysha, 2016).

As McGrath (2009) states, MNEs should beware of the hidden dependencies among different parts of firm's operations, and firing responsible people and replacing them with inexperienced ones - as redundancy does looks good for a while but ultimately undermines 'fundamental value proposition' to firm's customers. Therefore, redundancy needs to be 'planned' - a part of corporate strategy - and should be implemented carefully, 'without drawing the blood' of the enterprise (Copeland, 2003). More alarmingly, companies that adopt unplanned redundancy as a cost cutting and efficiency enhancing strategy often fail to compete with the rivals, as it makes them 'lean', 'mean' and 'lame', and eventually, they lose their competitive advantage (Mellahi \& Wilkinson, 2010; Gandolfi, 2010; Rigby, 2010; Guterman, 2009; Sutton, 2007). Thus, they ultimately fail to retain their business. Therefore, MNEs should not simply turn to redundancy for cost cutting or performance enhancing, as there are other choices for them worth considering first (Makin, 2013). Redundancy should rather be the last resort for MNEs to apply while downsizing (Redman and Wilkinson, 2009; p.385). However, such application again needs right 
preparation and arrangements, because the strategy can turn into a very costly one for MNEs (Dundon \& Rollinson, 2011, p.257), when considered the severance pay (Lewis, 1993), and related compensations, especially if it turns out to be an 'unfair dismissal' and the employer is taken to the court for compensation (Sheffi, 2005).

\section{Best Fit-redundancy Execution Model - A 3-Step Process:-}

MNEs, therefore, need to consider the long-term and short-terms effects and aftereffects of redundancy carefully before adopting it as a strategic option (Campbell-jamaison, et. al. 2007). Simultaneously, firms should strive to maintain the right policies, procedures and arrangements for redundancy announcement, selection and execution. In order to apply the strategy safely and get the best out of it, MNEs should follow the following three-step bestfit redundancy management model.

\section{Munshi's Best-fit Redundancy Management Model}

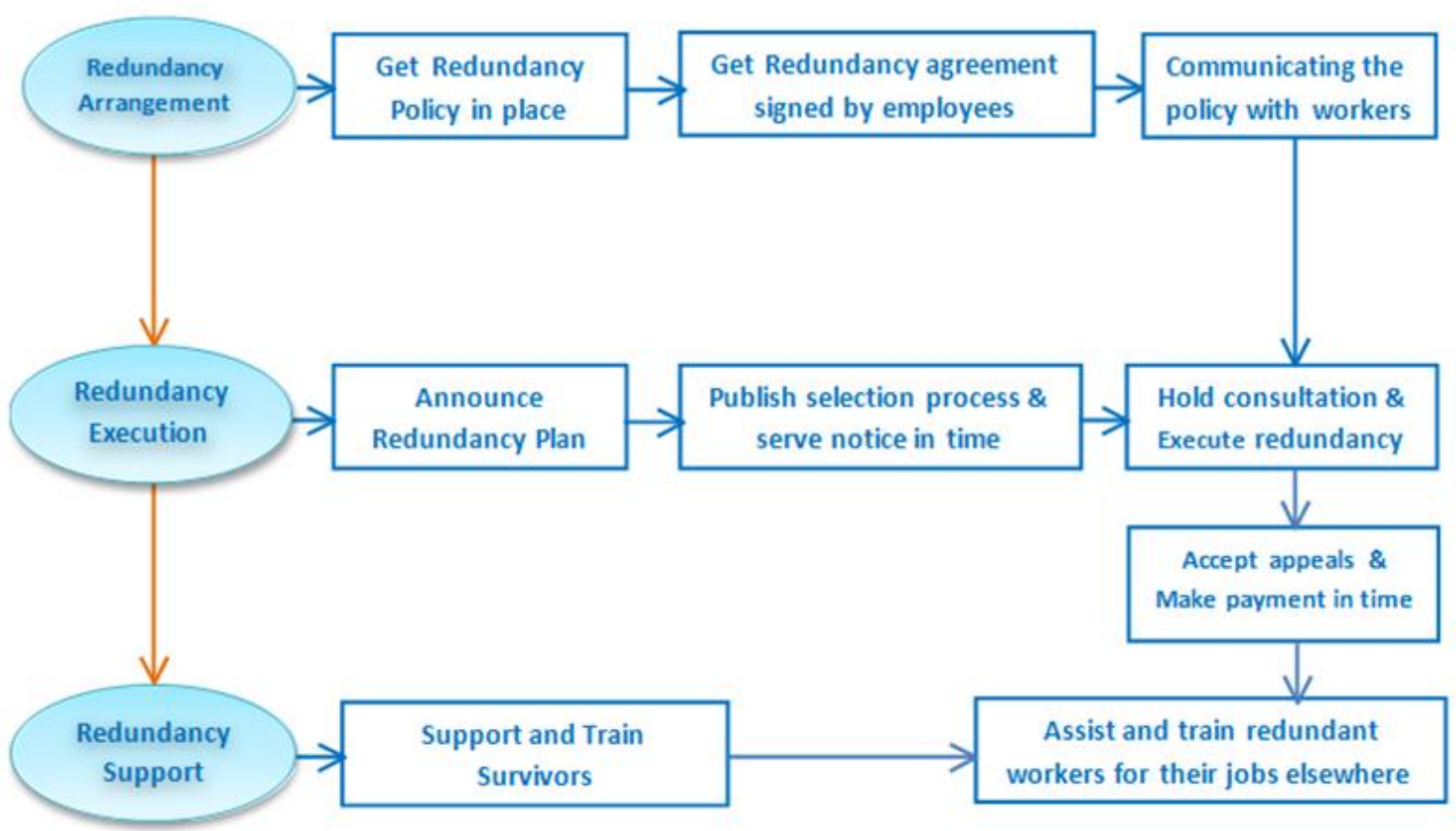

Step One:-Redundancy Arrangement

Every company in general should have a 'redundancy arrangement' in place and this should include a befitting redundancy policy, a redundancy agreement - an agreement confirming that redundancy situation may occur under certain external and/or internal conditions signed by every existing and new employee, and adequate circulation or communication of the policy so that employees become aware of it. More importantly, enterprise agreements should include the definition and reasons for redundancy occurrence. As evident from various enterprise agreements (), many MNEs have not even include the term 'redundancy' in their documents, let alone explain its reasons and procedures. Equally important for businesses to develop and communicate the selection and execution process of redundancy, which again need to be as fair and open as practicable.

Step Two:-Execution

If any redundancy situation arises, it should then be handled according to the 'selection' and 'redundancy execution' procedures, which should comprise of announcing redundancy plan in detail, publishing selection method(s) and serving appropriate notice to employees on time. The employer will also need to hold consultation with the employees or representatives, and listen to their views on the announcement, and if necessary, take further measures to make the whole process clear and open. Only after that they should start executing redundancy humanely and responsibly. 
Step Three:- Redundancy Supports

In the third phase, the employer will provide 'redundancy supports' - both to the redundant employees and to the survivors. For redundant employees, appeals or grievances will be accepted cordially and settled as per the regulations. At the same time, severance pay or redundancy compensation payment will be made on time. On the other hand, survivors must be given proper support and required training so that they can handle the stress - on other word, overcome 'survivor syndromes', and perform their regular and additional duties accordingly.

\section{Conclusion:-}

While job redundancy is a widely popular a strategy among MNEs around the world, it is not a proven practice that can help enterprises effectively cut cost, retain business or sustain with their core competence in the long-run (Gandolfi, 2010). Contrary to the beliefs and practices of MNEs, the practice can even do more harm than good to businesses (Sutton, 2009), and may cause 'organ failure' for them (Mellahi \& Wilkinson, 2010), due to its inconclusive impact around the globe (Gandolfi, 2010). Therefore, a cautious approach to its adaptation and execution is paramount to achieve its expected intended outcomes.

\section{References:-}

1. Allen, A. (2009); How to make redundancies; Chartered Institute of Personnel \& Development (Copyright of People Management), May 2009; UK, pp.10 - 11

2. Awino, D. O. (2017); Managing a Downsized Workforce: Dealing Fear after Retrenchment, HRManagement (Journal of the Institute of Human Resource Management VOL. 11 Issue 50); Accessed 11 May 2018 <https://www.ihrm.or.ke/asset/docs/media/ 9725_1484087997_DecJan_2017_(1).pdf>

3. Batton, J. and Gold, J. (2017); Human Resource Management: Theory and Practice, $6^{\text {th }}$ Edition, Palgrave (Macmillan), UK

4. Benson, E. (2009); 'Employment protection', in Gold, M. (ed.) Employment Policy in the European Union: Origins, themes and perspectives, London: Palgrave McMillan; pp.91 - 98

5. Bergstorm, O. and Arman, R. (2016); Increasing commitment after downsizing: the role of involvement and voluntary redundancies, Journal of Change Management, Accessed March 2018 <https://www.tandfonline.com/doi/abs/10.1080/ 14697017.2016.1252784>Blumberg, B, Cooper, D. R., Schindler, P. S. (2011), Business Research Methods; 3rd European Edition, McGraw-Hill Higher Education, Berkshire

6. Campbell-jamison, F., (2007); Downsizing in Britain and Its effects on Survivors and Their Organisations; Accessed 28 March 2018 <https://www.tandfonline.com/doi/abs/ 10.1080/10615800108248347>

7. Cheema, A. \& Bagchi, R. (2011); The Effect of Goal Visualization on Goal Pursuit: Implications for Consumers \& Managers; American Marketing Association; Journal of Marketing, Vol. 75 (March 2011); pp.109-123

8. Cheng, G. H., \& Chan, D. K. (2008); Who Suffers More from Job Insecurity? A Meta- Analytic Review; Applied Psychology: An International Review, 57 (2), pp.272 - 303

9. CIPD (2013); Are organisations losing the trust of their workers?, Accessed 11 May 2018 <https://www.cipd.co.uk/Images/megatrends_2013-organisations-losing-trust-of-workers_tcm18-11404.pdf>

10. Dibben, P., Klerck, G. \& Wood, G. (2011); Employment Relations (A critical and International Approach); Chartered Institute of Personnel and Development, London; pp.284 - 304

11. Fazey, M. (2010), Human Resource Policy, $1^{\text {st }}$ Edition, Tilde University Press, Australia

12. Flick, U. (2011); Introducing Research Methodology (A beginner's Guide to Doing a Research Project); SAGE Publications, London; pp $55-62$

13. Foot and Hook (2015), Introducing Human Resource Management, $7^{\text {th }}$ Edition, Pearson Education Ltd, UK

14. Gandolfi, F. (2010), New Developments in Reduction-in-Force (A Brief Historical Analysis of a Business Strategy); Journal of Management Research, Vol. 10, No. 1, April 2010

15. Gandolfi, F. and Hansson, M (2010), Reduction-in-force (RIF): New developments and a brief historical analysis, Accessed 01 March 2018 <www.researchgate.net>

16. Harrington, S (2016); Job cuts save money but can hurt business in the long-run; Accessed 23 April 2018 <https://theconversation.com/job-cuts-save-money-but-can-hurt-business-in-the-long-run-53581>

17. Makin, S (2013); Ten Top Tips: Avoid Redundancies; Accessed 26 May, 2018 <https://www.managementtoday.co.uk/ten-top-tips-avoid-redundancies/ article/ 1135743>

18. Martindale, N. (2009); Redundancy: Top $10 \quad$ Alternatives; Accessed 29 March 2018 <http://www.personneltoday.com/articles/2009/02/03/49198/ redundancy-top- 10-alternatives.html> 
19. McGrath, R. (2009); A Better Way to Cut Costs; Harvard Business review, Accessed 9 May 2018 <http://blogs.hbr.org/hbr/mcgrath/2009/03/a-better-way-to-cut-costs.html>

20. Mellahi, K. and Wilkinson, A. (2010); Slash and Burn or nip and tuck? Downsizing, Innovation and Human Resources; The International Journal of Human Resource Management, Vol. 21, Issue 13, 2010; pp $9-14$

21. Newton, R. (2011); Change Management (Financial Times Briefings), First Edition, Prentice Hall (Financial Times), UK; pp.26 - 59

22. O'Carroll, S (2009); Cut costs, not heads: 5 strategies to prepare for the upturn; Accessed 18 April 2018 <https://www.hcamag.com/hr-resources/hr-strategy/cut-costs-not-heads-5-strategies-to-prepare-for-the-upturn115345.aspx>

23. Patty, A. (2016); Australia has a comparatively high rate of worker redundancies following corporate downsizes; Accessed March 29, 2017 <https://www.smh.com.au/business/ workplace/ australia-has-acomparatively-high-rate-of-worker-redundancies-following-corporate-downsizes-20160407-go0yme.html>

24. Smithers, R. (2010); British Manufacture ring 'at risk of collapse in five years because of skill shortage; Accessed March 29, 2017 <https://www.theguardian.com/business/2010/sep/02/britishmanufacturing-collapse-five-years>

25. Stern, E (2012); From 'Valid Reason' To 'Genuine Redundancy' Redundancy Selection: A Question Of (Im)Balance? Accesses $19 \quad$ April 2018, <http://www.unswlawjournal.unsw.edu.au/wpcontent/uploads/2017/09/35-1-14.pdf >

26. Stone, R. J. (2014), Human Resource Management, $8^{\text {th }}$ Edition, Willey \& Sons, Australia

27. Sutton, B. (2009); Doing Layoffs Right; Harvard Business Review; Harvard Business School Publishing, 2009; pp.1 - 4

28. Thompson, J. and Martin. F. (2010); Strategic Management (Awareness \& Change); 6th Edition; South-Western (Cengage Learning), UK; pp.603 - 621

29. Wilkinson, A., Redman, T. and Dundon, T. (2017), Contemporary Human Resource Management: Text and Cases, $5^{\text {th }}$ Edition, Pearson Education Ltd, UK

30. Williams, D. K. and Scott, M. M (2012); Five Ways to Retain Employees Forever; Accessed 28 March 2018 $<$ https://hbr.org/2012/11/five-ways-to-retain-employees>

31. Enterprise Agreements:

32. ANZ Enterprise Agreement 2015-2016; Accessed $12 \quad$ March $2018 \quad$ http://www.fsunion.org.au/Upload/ANZ\%20Enterprise\%20Agreement\%202015\%20-\%202016.pdf>

33. Commonwealth Bank Enterprise Agreement 2017-2020; Accessed $12 \quad$ March 2018 <https://www.pc.gov.au/careers/enterprise-agreement/pc-enterprise-agreement-2017-2020.pdf>

34. NAB Enterprise $\quad$ Agreement 2016; $\quad$ Accessed $12 \quad$ March 2018 <http://www.fsunion.org.au/Upload/NAB/2016/Proposed\%20NAB\%20EB\%202016\%20FINAL\%20draft.pdf>

35. Westpac Group Enterprise Agreement 2016; Accessed 12 March $2018<$ http://www.fsunion.org.au/Upload/FWC\%20copy\%20Westpac\%20Group\%20EA\%202016.pdf> 